\title{
A COST-EFFECTIVE DECISION-MAKING ALGORITHM FOR INTEGRITY OF HMSCs: A MULTI-OBJECTIVE APPROACH
}

\author{
Ahmed Mohammed, Qian Wang \\ School of Engineering. University of Portsmouth \\ Portsmouth, UK \\ Ahmed.mohammed@port.ac.uk
}

\author{
Xiaodong Li \\ Department of Mathematics. University of Portsmouth \\ Portsmouth, UK
}

\begin{abstract}
In recent years, there has been a growing concern about safety and quality of food in the public society. This requires food suppliers or retailers who can monitor their food supply chains providing adequate information that can be easily accessed by customers who purchase food products in supermarkets. This can be achieved partially by implementing fast-growing IT techniques such as an integrated RFID (radio frequency identification)-based management system into an entire network of food supply chains. Nevertheless, this may lead to additional costs that need to be addressed when designing and implementing such an RFID-based food supply chain network. This paper presents a development of a multi-objective mathematical model that was used for quantifying a proposed design of a three-echelon Halal meat supply chain (HMSC) network, which is monitored by an integrated RFID-based management system. The study was aimed at maximizing the integrity of Halal meats, return of capital investment and minimizing costs in implementation of such a system into the HMSC network. A case study was also used for examining the validation and applicability of the developed HMSC model.
\end{abstract}

Keywords-RFID, Halal, supply chains, modeling, multiobjective optimization

\section{INTRODUCTION}

Today, it is essential for designing and implementing a costeffective food supply chain in order to gain a profitable share in the competitive market. Meantime, the issue in safety and quality for food is one of major concerns and consumers increasingly demand more transparent information on food they purchase in supermarkets. For many Muslim communities who live in countries like the UK, integrity of Halal food is also important. Thus, these consumers also demand more transparent information in terms of integrity of Halal food they purchase in local supermarkets.

The Islamic term of Halal means allowed or permitted in English translation and it is often used in association with food products, i.e., food products that are permissible for Muslims to eat or drink under the Islamic Shari'ah (laws). For instance, production of Halal meats needs to comply with the Islamic Shari'ah in each process of livestock feeding, slaughtering, packing, storing and transporting before being sold as Halal

The authors wish to thank the Higher Committee for Education Development (HCED) in Iraq for the financial support in this study. meats in supermarkets. If a specific process is not handled properly in a Halal way, retailers and consumers may regard these meat products as non-Halal. Today, consumption of Halal meats is a well-known diet among not merely Muslim but also many non-Muslim people and it is one of fastgrowing businesses in the world. Nevertheless, there is a little amount of research work relating HMSC-related design and implementation in an aspect of both customer satisfactions (of Halal meat integrity) and economic costs. Apparently, this area is overlooked by researchers [1], [2].

Gen [3] and Deb [4] proposed a multi-objective mathematical model in solving a practical supply chain design problem. Wheras other researchers applied this approach into a design of supply chains with different objectives as in [5], [6], [7]. Kannan [8] developed a mathematical model to examine a supply chain management in battery recycling. Amin [9] developed a mixed integer linear programming model that minimizes a total cost for multiple locations in a closed-loop supply chain network. Duffuaa [10] developed a multiobjective model with three objectives, which were aimed to maximize profit, income and product uniformity based on a ranking system that rates quality for those inspected products to determine different selling prices in the market. Amin [11] developed a multi-objective fuzzy programming model that was used for configuring a closed-loop supply chain network, which consists of disassembly, refurbishing and disposal sites. Three objectives were considered in optimizing profit, suppliers' selections and defect rates. Lee [12] proposed a nonlinear multi-objective programming model for managing a coal supply chain with three objectives: costs of facility location, path selection and transportation. Wu [13] developed a mathematical model for a closed loop supply chain with two objectives using a scenario-based programming. Similar studies were published by Vahdani [14] in designing a closed loop supply chain using a fuzzy multi-objective optimization model. Samanlioglu [15] developed a multi-objective location routing model in configuring a supply chain management of hazmat recycling. Cakravastia [16] provided a mixed integer multi-objective model for determining a selection of suppliers in designing a supply chain. Tzeng [17] developed a production and distribution model using a multi-objective programming in order to maximize the total profit by improving the service level. 


\section{THE MATHEMATICAL MODEL}

Fig. 1 illustrates a three-echelon HMSC network which consists of farms, abattoirs and retailers. To ensure the integrity of Halal meat products, an RFID (radio frequency identification) based monitoring system was proposed to monitor every process during production (at farms and abattoirs) and transportation. Obviously, implementation of the proposed RFID-based monitoring system requires capital investments or additional costs, which are one of key measures in designing and implementing a cost-effective HMSC. Thus, a mathematical model with the multi-objective approach was developed as an aid for determining investment costs, return on investments and integrity in numbers of Halal meat products. The three objectives include the objective (equation 5) to minimize the total cost of investments, the objective (equation 6) to maximize the integrity halal meats and the objective (equation 7) to maximize the return of investment (profit).

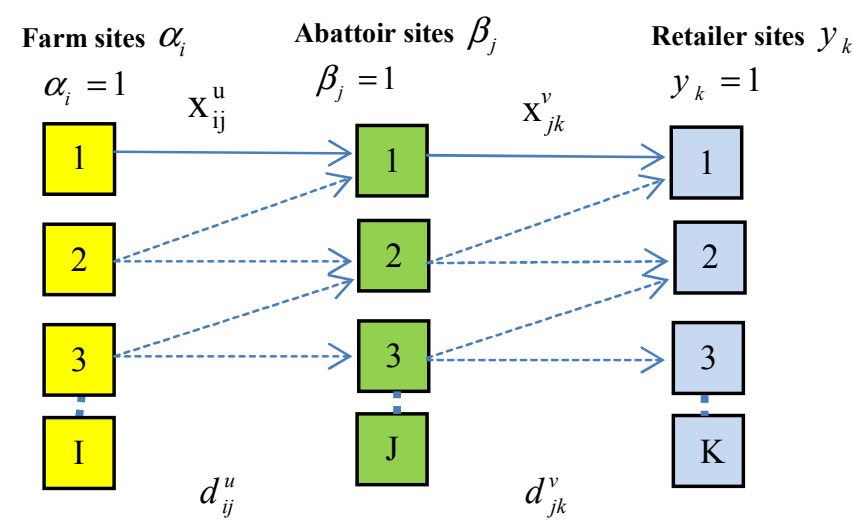

Fig. 1. The three-echelon HMSC

Sets, parameters and decision variables are as follows:

Sets:

$I$

$J$

set of farms $i \in I$

K

set of abattoirs $j \in J$

set of retailers $k \in K$

Parame

ters:

$C_{i}^{E, \alpha}$

equipment $(E)$ cost (GBP) required for farm $i$

$C_{i}^{\mathrm{E}, \beta}$

equipment $(E) \operatorname{cost}(\mathrm{GBP})$ required for abattoir $j$

$C_{i}^{\mathrm{I}, \alpha}$

$C_{j}^{I, \beta}$

$C_{i j}^{\mathrm{T}, \mathrm{u}}$

implementation $(I)$ cost $(\mathrm{GBP})$ required for farm $i$ implementation (I) cost (GBP) required for abattoir $j$ unit transportation $(T)$ cost (GBP) per mile from farm $i$ to abattoir $j$

$C_{j k}^{\mathrm{T}, \mathrm{v}} \quad$ unit transportation $(T)$ cost (GBP) per mile from abattoir $j$ to retailer $k$

$d_{i j}^{\mathrm{u}} \quad$ travel distance (mile) from farm $i$ to abattoir $j$ $d_{j k}^{v} \quad$ travel distance (mile) from abattoir $j$ to retailer $k$

$W \quad$ transportation capacity (units) per vehicle

$\mathrm{S}_{\mathrm{i}}^{\alpha} \quad$ maximum supply capacity (units) of farm $i$

$\mathrm{S}_{\mathrm{j}}^{\beta} \quad$ maximum supply capacity (units) of abattoir $j$

$\mathrm{D}_{\mathrm{j}}^{\beta} \quad$ minimum demand (in units) of abattoir $j$

$\mathrm{D}_{\mathrm{k}} \quad$ minimum demand (in units) of retailer $k$

$\mathrm{P}_{\mathrm{ij}}^{\mathrm{u}} \quad$ integrity percentage through first transportation link $\mathrm{u}$ from farm $i$ to abattoir $j$

$\mathrm{P}_{\mathrm{jk}}^{\mathrm{v}} \quad$ integrity percentage through second transportation link v from abattoir $j$ to retailer $k$

$\mathrm{R}_{\mathrm{i}}^{\alpha} \quad$ return of investment (GBP) for farm $i$

$\mathrm{R}_{\mathrm{j}}^{\beta} \quad$ return of investment (GBP) per item for abattoir $j$

$\mathrm{G}^{1} \quad$ goal of the objective 1

$\mathrm{G}^{2} \quad$ goal of the objective 2

$\mathrm{G}^{3} \quad$ goal of the objective 3

Variables:

$\mathrm{X}_{\mathrm{ij}}^{\mathrm{u}} \quad$ quantity of units transported through first transportation link $\mathrm{u}$ from farm $i$ to abattoir $j$

$\mathrm{x}_{\mathrm{jk}}^{\mathrm{v}} \quad$ quantity of units transported through second transportation link $\mathrm{v}$ from abattoir $j$ to retailer $k$

$\mathrm{y}_{\mathrm{i}}^{\alpha}\left\{\begin{array}{l}1: \text { if } \operatorname{farm} i \text { is open } \\ 0: \text { otherwise }\end{array}\right.$

$\mathrm{y}_{\mathrm{j}}^{\beta}\left\{\begin{array}{l}1: \text { if abattoir } j \text { is open } \\ 0: \text { otherwise }\end{array}\right.$

$\mathrm{n}^{1} \quad$ negative deviation variable of the objective 1

$\mathrm{n}^{2} \quad$ negative deviation variable of the objective 2

$\mathrm{n}^{3} \quad$ negative deviation variable of the objective 3

$\mathrm{p}^{1} \quad$ positive deviation variable of the objective 1

$\mathrm{p}^{2} \quad$ positive deviation variable of the objective 2

$\mathrm{p}^{3} \quad$ positive deviation variable of the objective 3

The goal programming approach was employed, i.e., each objective was given a goal value to be approached by minimizing the undesired deviation towards to the goal value to be achieved. To this aim, each objective was solved individually and its value was given as a target for the approaching function. Equations 1-4 show the solution functions for tackling the problem of the developed multiobjective model.

$$
\begin{aligned}
& \min \mathrm{Z} \\
& \frac{\mathrm{n}^{1}}{\mathrm{G}^{1}} \leq \mathrm{Z}
\end{aligned}
$$




$$
\begin{aligned}
& \frac{p^{2}}{G^{2}} \leq Z \\
& \frac{p^{3}}{G^{3}} \leq Z
\end{aligned}
$$

Objective function 1:

$\sum_{i \in I}\left(C_{i}^{E, \alpha}+C_{i}^{l, \alpha}\right) y_{i}^{\alpha}+\sum_{j \in J}\left(C_{j}^{E, \beta}+C_{j}^{L, \beta}\right) y_{j}^{\beta}$

$$
+\sum_{i \in I} \sum_{j \in J} C_{i j}^{T, u}\left[\frac{x_{i j}^{u}}{W}\right] d_{i j}^{u}+\sum_{j \in J k \in K} C_{j k}^{T, v}\left[\frac{x_{j k}^{v}}{W}\right] d_{j k}^{v}+n^{1}-p^{1}=G^{1}
$$

Objective function 2:

$$
\sum_{i \in I} \sum_{j \in J} P_{i j}^{u} x_{i j}^{u}+\sum_{j \in J} \sum_{k \in K} P_{j k}^{v} x_{j k}^{v}+n^{2}-p^{2}=G^{2}
$$

Objective function 3 :

$$
\sum_{i \in I} \sum_{j \in J} R_{i}^{\alpha} x_{i j}^{u}+\sum_{j \in J} \sum_{k \in K} R_{j}^{\beta} x_{j k}^{v}+n^{3}-p^{3}=G^{3}
$$

Constraints:

$$
\begin{array}{cc}
\sum_{i \in I} \mathrm{x}_{i j}^{u} \leq \mathrm{S}_{i}^{\alpha} \mathrm{y}_{i}^{\alpha} & \forall \mathrm{j} \in \mathrm{J} \\
\sum_{j \in J} \mathrm{x}_{\mathrm{jk}}^{\mathrm{v}} \leq \mathrm{S}_{\mathrm{j}}^{\beta} \mathrm{y}_{\mathrm{j}}^{\beta} & \forall \mathrm{k} \in K \\
\sum_{\mathrm{i} \in \mathrm{I}} \mathrm{x}_{\mathrm{ij}}^{\mathrm{u}} \geq \mathrm{D}_{\mathrm{j}}^{\beta} & \forall \mathrm{j} \in \mathrm{J} \\
\sum_{\mathrm{j} \in \mathrm{J}} \mathrm{X}_{\mathrm{jk}}^{\mathrm{v}} \geq \mathrm{D}_{\mathrm{k}} & \forall \mathrm{k} \in \mathrm{K} \\
\mathrm{D}_{\mathrm{j}}^{\beta} \geq \sum_{\mathrm{k} \in \mathrm{K}} \mathrm{x}_{\mathrm{jk}}^{\mathrm{v}} & \forall \mathrm{j} \in \mathrm{J} \\
x_{i j}^{u} \text { integer } & \\
x_{j k}^{v} \text { integer } & \\
y_{i}^{\alpha} \text { binary } & \\
y_{j}^{\beta} \text { binary } &
\end{array}
$$

Where, equations 8 and 9 are supply capacity constraints in quantity; and equation 10-12 are demand constraints in quantity.

\section{APPLICATION AND VALIDATION}

In order to examine applicability and validation of the developed mathematical model, a case study was applied. Table I shows data collected and provided from farms, abattoirs and retailers by the Halal Meat Committee (HMC) in the UK [18]. The Google map was used to estimate travel distances between farms and abattoirs, and between abattoirs and retailers. In case study A, London-South West area was considered, it includes 5 farms, 6 abattoirs and 11 retailers. In case study B, London-South East area was considered, it includes 5 farms, 6 abattoirs and 3 retailers.
TABLE I. DATA FOR CASE A AND B

\begin{tabular}{ll}
\hline Case A / London - South West \\
\hline$I=5$ & $\mathrm{C}_{\mathrm{j}}^{\mathrm{E}, \beta}=4 \mathrm{~K}-7.5 \mathrm{~K}$ \\
$J=6$ & $\mathrm{C}_{\mathrm{j}}^{\mathrm{I}, \beta}=700-1.2 \mathrm{~K}$ \\
$K=11$ & $S_{i}^{\alpha}=1.2 \mathrm{~K}-2.5 \mathrm{~K}$ \\
$\mathrm{C}_{\mathrm{i}}^{\mathrm{E}, \alpha}=4 \mathrm{~K}-8 \mathrm{~K}$ & $S_{j}^{\beta}=1 \mathrm{~K}-1.8 \mathrm{~K}$ \\
$\mathrm{C}_{\mathrm{i}}^{\mathrm{l}, \alpha}=400-800$ & $\mathrm{D}_{\mathrm{j}}^{\beta}=300-1.5 \mathrm{~K}$ \\
$\mathrm{D}_{\mathrm{k}}^{\gamma}=50-100$ & $\mathrm{~d}_{\mathrm{ij}}^{\mathrm{u}}=23-410$ \\
$\mathrm{P}_{\mathrm{ij}}^{\mathrm{u}}=0.85-0.98$ & $\mathrm{~d}_{\mathrm{jk}}^{\mathrm{v}}=110-174$ \\
$\mathrm{P}_{\mathrm{jk}}^{\mathrm{v}}=0.85-100$ & $W=100$ \\
$R_{i}^{\alpha}=30-100$ & $R_{j}^{\beta}=15-100$ \\
\hline $\mathrm{Case}^{\alpha} \mathbf{B} /$ London - South & $\mathbf{E a s t}^{\mathrm{a}}$ \\
\hline$I=5$ & $\mathrm{C}_{\mathrm{j}}^{\mathrm{E}, \beta}=4 \mathrm{~K}-7.5 \mathrm{~K}$ \\
$J=6$ & $\mathrm{C}_{\mathrm{j}}^{\mathrm{I}, \beta}=700-1.2 \mathrm{~K}$ \\
$K=3$ & $S_{i}^{\alpha}=1.2 \mathrm{~K}-2.5 \mathrm{~K}$ \\
$\mathrm{C}_{\mathrm{i}}^{\mathrm{E}, \alpha}=4 \mathrm{~K}-8 \mathrm{~K}$ & $S_{j}^{\beta}=1 \mathrm{~K}-1.8 \mathrm{~K}$ \\
$\mathrm{C}_{\mathrm{i}}^{\mathrm{l}, \alpha}=400-800$ & $\mathrm{D}_{\mathrm{j}}^{\beta}=600-1.5 \mathrm{~K}$ \\
$\mathrm{D}_{\mathrm{k}}^{\gamma}=100-200$ & $\mathrm{~d}_{\mathrm{ij}}^{\mathrm{u}}=23-400$ \\
$\mathrm{P}_{\mathrm{ij}}^{\mathrm{u}}=0.90-0.98$ & $\mathrm{~d}_{\mathrm{jk}}^{\mathrm{v}}=110-162$ \\
$\mathrm{P}_{\mathrm{jk}}^{\mathrm{v}}=0.85-100$ & $W=100$ \\
$R_{i}^{\alpha}=60$ & $R_{j}^{\beta}=40$ \\
\hline &
\end{tabular}

Table II shows computed results when each objective function (OF) was optimized individually for cases A and B, respectively.

TABLE II. COMPUTED RESULTS FOR CASES A AND B

\begin{tabular}{cccc}
\hline & $\min \mathbf{O F}_{\mathbf{1}}$ & $\max \mathbf{O F} \mathbf{F}_{\mathbf{2}}$ & $\max \mathbf{O F}_{\mathbf{3}}$ \\
\hline \multicolumn{3}{c}{$\boldsymbol{C a s e} \boldsymbol{A}$} \\
$\mathrm{OF}_{1}$ & 279922 & 550358 & 559646 \\
$\mathrm{OF}_{2}$ & 10289 & 14093 & 13913 \\
$\mathrm{OF}_{3}$ & 559000 & 793600 & 793630 \\
\hline \multicolumn{4}{c}{$\boldsymbol{C a s e} \boldsymbol{B}$} \\
$\mathrm{OF}_{1}$ & $\min \mathbf{O F}_{\mathbf{1}}$ & $\mathbf{m a x} \mathbf{O F}_{\mathbf{2}}$ & $\mathbf{m a x} \mathbf{O F}_{\mathbf{3}}$ \\
$\mathrm{OF}_{2}$ & 90480 & 502860 & 507945 \\
$\mathrm{OF}_{3}$ & 210000 & 258777 & 258615 \\
\hline
\end{tabular}

By analyzing these results, the objective functions are conflicted when optimizing one objective value that leads to an increase of the undesired values for the two others. For instance, by obtaining a minimum value for $\mathrm{OF}_{1}$, it yields worst values for both $\mathrm{OF}_{2}$ and $\mathrm{OF}_{3}$. To gain a trade-off solution, the goal programing method was utilized with the three objective values shown in Table II as targets for the goal programming solution function. Table III illustrates the obtained results for cases A and B. 
TABLE III. COMPUTED RESULTS FOR CASES A AND B USING THE GOAL PROGRAMMING APPROACH

\begin{tabular}{|c|c|c|c|c|c|}
\hline $\begin{array}{l}\text { Solution } \\
\text { number }\end{array}$ & $\begin{array}{l}\min \\
\mathrm{OF}_{1}\end{array}$ & $\begin{array}{l}\max \\
\mathrm{OF}_{2}\end{array}$ & $\begin{array}{l}\max \\
\mathrm{OF}_{3} \\
\end{array}$ & $\begin{array}{l}\text { Open } \\
\text { farms }\end{array}$ & $\begin{array}{l}\text { Open } \\
\text { abattoirs }\end{array}$ \\
\hline \multicolumn{6}{|c|}{ Case A } \\
\hline 1 & 293411 & 10575 & 577060 & $1,3,4,5$ & $1,2,4,5,6$ \\
\hline 2 & 542592 & 13899 & 793600 & $1,2,3,4,5$ & $1,2,3,4,5,6$ \\
\hline 3 & 554487 & 13843 & 793600 & $1,2,3,4,5$ & $1,2,3,4,6$ \\
\hline \multicolumn{6}{|c|}{ Case B } \\
\hline 1 & 549558 & 13803 & 793600 & $1,2,3,4,5$ & $1,2,3,4,6$ \\
\hline 2 & 497660 & 258589 & 654000 & $1,2,3,4,5$ & $1,2,3,4,5,6$ \\
\hline 3 & 477947 & 258615 & 654000 & $1,2,3,4,5$ & $1,3,5$ \\
\hline
\end{tabular}

As shown in Table III, these solutions are associated with allocations of supply chain sites of farms and abattoirs that need to be opened. In a real life, one of these solutions can be selected based on preferences of decision makers. For this case study, solution one for case A was determined by having four farms and five abattoirs using $\mathrm{OF}_{1}$ (293411), $\mathrm{OF}_{2}$ (10575) and $\mathrm{OF}_{3}$ (577060). Solution three for case $\mathrm{B}$ was decided with five farms and three abattoirs using $\mathrm{OF}_{1}$ (477947), $\mathrm{OF}_{2}$ (258615) and $\mathrm{OF}_{3}(654000)$.

Finally, based on the chosen solutions, the optimized quantity product flow between the HMSCs sites is given in Table IV. For instance, farm one should supply livestock to abattoir one, five and six with the following livestock quantity: 1200 items are sent to abattoir four, 800 items are sent to abattoir five and 340 items are sent to abattoir six. Abattoir one should supply Halal meat products to retailer one, three and six with the following meat quantity: 850 items are sent to retailer one, 210 items are sent to retailer three and 690 items are sent to retailer six.

TABLE IV. QUANTITY PRODUCT FLOW FOR CASES A AND B

\begin{tabular}{|c|c|c|c|c|c|}
\hline $\begin{array}{c}\text { Sites } \\
(\text { Link u) }\end{array}$ & $\begin{array}{l}\text { Quantity } \\
\text { (Items) }\end{array}$ & $\begin{array}{c}\text { Sites } \\
(\text { Link v) }\end{array}$ & $\begin{array}{l}\text { Quantity } \\
\text { (Items) }\end{array}$ & $\begin{array}{c}\text { Sites } \\
(\text { Link v) } \\
\end{array}$ & $\begin{array}{c}\text { Quantity } \\
\text { (Items) }\end{array}$ \\
\hline \multicolumn{6}{|c|}{ Case $A$} \\
\hline $\mathrm{u}_{1,4}$ & 1200 & $\mathrm{~V}_{1,1}$ & 850 & $\mathrm{v}_{6,10}$ & 180 \\
\hline $\mathrm{u}_{1,5}$ & 800 & $\mathrm{v}_{1,3}$ & 210 & $\mathrm{v}_{4,6}$ & 270 \\
\hline $\mathrm{u}_{1,6}$ & 340 & $\mathrm{v}_{1,6}$ & 690 & & \\
\hline $\mathrm{u}_{3,1}$ & 800 & $\mathrm{v}_{2,5}$ & 290 & & \\
\hline $\mathrm{u}_{3,4}$ & 1200 & $\mathrm{v}_{2,10}$ & 100 & & \\
\hline $\mathrm{u}_{3,5}$ & 1000 & $\mathrm{v}_{2,8}$ & 160 & & \\
\hline $\mathrm{u}_{3,6}$ & 290 & $\mathrm{v}_{2,11}$ & 700 & & \\
\hline $\mathrm{u}_{4,1}$ & 100 & $\mathrm{v}_{4,6}$ & 850 & & \\
\hline $\mathrm{u}_{4,4}$ & 110 & $\mathrm{v}_{4,7}$ & 450 & & \\
\hline $\mathrm{u}_{4,6}$ & 550 & $\mathrm{v}_{5,9}$ & 110 & & \\
\hline $\mathrm{u}_{4,5}$ & 130 & $\mathrm{v}_{5,2}$ & 220 & & \\
\hline $\mathrm{u}_{5,2}$ & 1100 & $\mathrm{v}_{5,5}$ & 359 & & \\
\hline $\mathrm{u}_{5,4}$ & 230 & $\mathrm{v}_{6,6}$ & 100 & & \\
\hline $\mathrm{u}_{5,6}$ & 170 & $\mathrm{v}_{6,8}$ & 330 & & \\
\hline \multicolumn{6}{|c|}{ Case B } \\
\hline $\mathrm{u}_{1,1}$ & 1200 & $\mathrm{~V}_{1,3}$ & 850 & $\mathrm{~V}_{5,2}$ & 180 \\
\hline $\mathrm{u}_{1,5}$ & 800 & $\mathrm{~V}_{1,7}$ & 210 & $\mathrm{~V}_{5,3}$ & 270 \\
\hline $\mathrm{u}_{2,3}$ & 800 & $\mathrm{~V}_{1,8}$ & 690 & $\mathrm{~V}_{5,5}$ & 330 \\
\hline $\mathrm{u}_{3,3}$ & 1000 & $\mathrm{v}_{1,10}$ & 690 & $\mathrm{~V}_{5,7}$ & 810 \\
\hline $\mathrm{u}_{3,5}$ & 290 & $\mathrm{v}_{1,11}$ & 120 & $\mathrm{~V}_{5,8}$ & 1100 \\
\hline $\mathrm{u}_{4,1}$ & 1200 & $v_{3,5}$ & 290 & $\mathrm{~V}_{5,10}$ & 100 \\
\hline $\mathrm{u}_{4,3}$ & 1000 & $\mathrm{~V}_{3,8}$ & 160 & $\mathrm{~V}_{3,1}$ & 160 \\
\hline $\mathrm{u}_{4,5}$ & 290 & $\mathrm{~V}_{3,10}$ & 700 & $\mathrm{~V}_{3,6}$ & 700 \\
\hline $\mathrm{u}_{5,1}$ & 610 & $\mathrm{~V}_{3,11}$ & 100 & $\mathrm{~V}_{5,11}$ & 560 \\
\hline
\end{tabular}

\section{SUMMARY}

This paper presents a development of a three-objective mathematical model based on an RFID-based three-echelon HMSC. The developed multi-objective mathematical model can be used as a reference for HMSC designers in finding a trade-off solution in minimizing the total investment cost, maximizing the integrity of Halal meats and maximizing the return of investment. A case study was carried out in order to validate the developed mathematical model. The initial results indicate that this is a useful and effective way as an aid for designing and implementing a cost-effective RFID-enabled monitoring mechanism to enhance the integrity of the proposed HMSC.

\section{REFERENCES}

[1] Lodhi, A., "Understanding Halal Food Supply Chain," 1ST edition, HFRC, London: UK, 2009.

[2] Zulfakar, M.H., Jie, F. \& Chan, C., "Halal Food Supply Chain Integrity: From A Literature Review To A Conceptual Framework," Proceeding of the 10th ANZAM / Operations Supply Chain and service management. Melbourne, pp. 1-23, 14-15 June 2012

[3] Gen, M. \& Cheng, R., "Genetic Algorithms and Engineering Design," John Wiley \& Sons, New York.G, 1997.

[4] Deb, K., "Multi-Objective Optimization using Evolutionary Algorithms," New York, John Wiley \& Sons, 2001.

[5] Barros, A.I., Dekker, R. \& Scholten, V., "A two-level network for recycling sand: A case study," Eur. J. Oper. Res, Vol. 110, No. 2, pp. 199-214, 1998.

[6] Jayaraman, V., Guige Jr, V.D.R. \& Srivastava, R., "A closed-loop logistics model for manufacturing," J. Oper. Res. Soc., Vol. 50, No. 5, pp. 497-508 1999.

[7] Krikke, H., R., Van Harten, A. \& Schuur, P.C., "Reverse logistic network re-design for copiers," OR Spektrum. Vol. 21, No. 3, pp. 381409.

[8] Kannan, G., Sasikumar, P. \& Devika, K., “A genetic algorithm approach for solving a closed loop supply chain model: a case of battery recycling," Appl. Math.Model, Vol. 34, No. 3, pp. 655-670, 2010.

[9] Amin, S.H. \& Zhang, G., "A multi-objective facility location model for closed-loop supply chain network under uncertain demand and return," Applied Mathematical Modelling, Vol. 37, No. 6, pp. 4165-4176, 2013.

[10] Duffuaa, S.O. \& El-Ga'aly, A., "A multi-objective mathematical optimization model for process targeting using $100 \%$ inspection policy," Applied Mathematical Modelling, Vol. 37, No. 3, pp. 1545-1552, 2013.

[11] Amin, S.H \& Zhang, G., "An integrated model for closed-loop supply chain configuration and supplier selection: Multi-objective approach," Expert Systems with Applications, Vol. 39, No. 4, pp. 6782-6791, 2012.

[12] Lee, D. \& Dong, M., "Dynamic network design for reverse logistics operations under uncertainty," Transport. Res. Part E, Vol. 451, No. 1, pp. 61-71, 2009.

[13] Wu, J., Li, K., "Dynamic Coal Logistics Facility Location under Demand Uncertainty," Open Journal of Social Sciences, china: Sceintific research, Vol. 2, pp. 33-39, 2014.

[14] Vahdani, B., Tavakkoli-Moghaddam, R., Modarres, M. \& Baboli, A., “ Reliable design of a forward/reverse logistics network under uncertainty: a robust-M/M/c queuing model," Transport. Res. Part E, Vol. 48, No. 6, pp. 1152-1168, 2012.

[15] Samanlioglu, F., "A multi-objective mathematical model for the industrial hazardous waste location-routing problem," European Journal of Operational Research, Vol. 226, No. 2, pp. 332-340, 2013.

[16] Cakravastia, A., Toha, I.S. \& Nakamura, N., "A two-stage model for the design of supply chain networks," Int. J. Prod. Econ., Vol. 80, No. 3, pp. 231-248.M. Young, The Technical Writer's Handbook. Mill Valley, CA: University Science, 2002. 
[17] Tzeng, G.-T., Hung, Y.-M. \& Chang, M.-L., "Multiple Objective Planning for Production and Distribution Model of Supply Chain: Case of Bicycle Manufacturer," Journal of scientific and industrial research, Vol. 65, pp. 309-320, 2006.
[18] HMC. (UK), "http://www.halalhmc.org/certified-outlets.htm", URL: http://www.halalhmc.org/certified-outlets-results.htm\#result. 